\title{
REPRESENTAÇÕES DIDÁTICAS DO BRASIL COLONIAL ${ }^{1}$
}

\section{Renilson Rosa Ribeiro}

\section{RESUMO}

Este artigo analisa as representações criadas pelos livros didáticos da disciplina sobre o Brasil colonial, procurando perceber como as proposições lançadas por autores como K. F. Von Martius, Francisco Adolfo Varnhagen e João Capistrano de Abreu constituíram uma ordem discursiva para a escrita da sua história em livros e livros didáticos a partir da segunda metade do século XIX e ao longo do século passado.

\section{PALAVRAS-CHAVE}

História; Ensino; Livro didático; Brasil-Colônia

\section{DIDACTICS REPRESENTATIONS OF COLONIAL BRAZIL}

\section{ABSTRACT}

This article analyses the representations created by textbooks about the colonial past of Brazil, trying to identify how the propositions presented by authors like K. F. Von Martius, Francisco Adolfo Varnhagen e João Capistrano de Abreu established a discursive order for the writing of the Brazilian history in books and textbooks from de second half of nineteenth century to the last century.

\section{KEYWORDS}

History; Teaching; Textbooks; Brazil-Colony

\footnotetext{
${ }^{1}$ Artigo originalmente apresentado como comunicação no Simpósio Temático "Ensino de História: Trajetórias e Novas Perspectivas” - IV Encontro Regional de História - ANPUH/MT e XII Semana de História - UFMT/Campus Rondonópolis, realizado entre 05 e 09 de março de 2007.
} 


\section{LUGARES IDENTITÁRIOS}

Marc Ferro [s.d.], nas primeiras linhas do seu conhecido livro a respeito da História ensinada às crianças em diferentes partes do mundo, afirmou que “a imagem que nós temos dos outros povos ou de nós mesmos é associada à história que nos foi contada quando éramos crianças”. Ele argumentou que mesmo que a essas imagens outras viessem a se misturar ao longo do tempo, eram as primeiras que permaneceriam constituindo-se em traços marcantes de nossas primeiras curiosidades, desejos e emoções.

Na construção dessas primeiras imagens sobre os mais diversos temas históricos é impossível ignorar o papel desempenhado pela tríade escola, livro didático e professor. Embora saibamos, por exemplo, que a mídia, por intermédio de filmes, novelas, séries e documentários, influencie nas interpretações das pessoas sobre os conteúdos históricos, a História ensinada nos tempos escolares continua a assumir grande destaque na formação da idéia de história presente na mente da maioria da população. E os livros didáticos têm sido as grandes referências para as narrativas históricas que povoam o universo cultural dos indivíduos.

Fonte de investimento e, ao mesmo tempo, de preocupação, este objeto colonizador sempre suscitou e tem suscitado debates dentro e fora das instituições (ministérios, secretarias, escolas, editoras, universidades) sobre a sua importância na constituição de identidades - um locus privilegiado de jogo de identidades (HALL, 2002).

Com base nestas observações, este artigo realizará uma análise das representações criadas pelos livros didáticos da disciplina sobre o Brasil colonial, procurando perceber como as proposições lançadas por autores como K. F. Von Martius, Francisco Adolfo Varnhagen e João Capistrano de Abreu constituíram uma ordem discursiva para a escrita da sua história em livros e livros didáticos a partir da segunda metade do século XIX e ao longo do século passado. Temáticas como as o descobrimento, a formação da sociedade colonial, conquista territorial e as bandeiras, revoltas coloniais entre outras têm sido privilegiados pelos autores na composição das imagens do Brasil colonial em seus livros didáticos. E, neste caso também, como analisaremos aqui, os autores, dentro de suas particularidades e contextos, não fugiram ao roteiro apresentado por estes ilustres intérpretes do Brasil. 
O universo de fontes e as possibilidades de pesquisa são diversas para tratar o assunto. Por esta razão, realizamos um recorte que permitisse uma análise do tema das representações do passado colonial articulada com as tendências historiográficas e as propostas programáticas. Na eleição das fontes, escolhemos alguns livros didáticos de História do Brasil representativos de quatro períodos que consideramos relevantes na história do ensino da disciplina no Brasil ${ }^{2}$. 1) aqueles produzidos no Brasil império, no contexto do segundo reinado, influenciado pela escrita de uma história presa aos pressupostos do Instituto Histórico e Geográfico Brasileiro (IHGB) e, conseqüentemente, vinculado ao projeto monárquico, justificado pelo elogio à colonização. 2) os produzidos no período republicano, do final do século XIX a 1930, marcados por uma visão épica da história, tendendo à depreciação do passado colonial no Brasil. 3) os livros fabricados por uma vertente nacionalista ou dela tributários, de 1930 até aproximadamente de 1980. 4) e os livros didáticos concebidos no contexto de propostas curriculares pautadas pela crítica à chamada “História Oficial” elitizada e nacionalista, publicados entre 1980 e 2000. Devemos ressaltar que não consideramos essas fases homogêneas e em absoluto distintas e separadas umas das outras. Entretanto, elas expressam tendências perceptíveis na trajetória do ensino de História no Brasil ${ }^{3}$.

\section{FABRICAÇÕES DO BRASIL COLÔNIA NOS LIVROS DIDÁTICOS}

Os primeiros livros didáticos de História foram publicados no Brasil em meados do século XIX. Eles se inspiravam nos manuais europeus de história universal, sobretudo nos franceses, que apresentavam uma concepção européia e cristã da história, na qual as crianças e jovens brasileiros deveriam se espelhar (BITTENCOURT, 1993).

Nos colégios freqüentados pelos filhos das elites, chegava-se a adotar as próprias edições originais desses manuais franceses. Um dos autores de destaque era Victor Duruy, historiador que chegou ao posto de ministro da França. No final do século XIX, em meio às

\footnotetext{
${ }^{2}$ Livros didáticos analisados: ALENCAR, Francisco et al. Brasil Vivo: Um Nova História da nossa Gente, Volume $1,1^{0}$ grau, 12 ed. Petrópolis, RJ: Vozes, 1992; HERMIDA, Antonio J. Borges. História do Brasil, 5 a série. São Paulo: Companhia Editora Nacional, s.d.; HOLANDA, Sérgio Buarque de et al. História do Brasil - Curso Moderno (Das Origens à Independência), $5^{\text {a }}$ série, Estudos Sociais. São Paulo: Companhia Editora Nacional, 1975; MACEDO, Joaquim Manuel de. Lições de História do Brasil para uso das escolas de instrucção primaria. 10 ed. Rio de Janeiro: H. Garnier, 1907; PILLETI, Nelson \& PILLETI, Claudino. História \& Vida - Brasil: Da Pré-História à Independência, Volume $1,1^{\circ}$ grau, 4 ed. São Paulo: Editora Ática, 1991; POMBO, José Francisco Rocha. História do Brasil. 6 ed. revista e atualizada por Helio Vianna. São Paulo: Companhia Melhoramentos de São Paulo, 1952; RIBEIRO, João. História do Brasil - curso médio, 17 ed. revista e completada por Joaquim Ribeiro. Rio de Janeiro: Livraria Francisco Alves, 1935; SILVA, Joaquim. História do Brasil para a primeira série ginasial. 8 ed. São Paulo: Companhia Editora Nacional, 1951.

${ }^{3}$ Essa periodização segue a apresentada por Thais Nívia de Lima e Fonseca (SIMAN; FONSECA, 2001).
} 
reformas educacionais conduzidas pelo regime republicano, outro francês, Charles Seignobos, era o autor preferido. Nestes dois manuais, o conceito de civilização era recorrente: o imperialismo europeu conquistava os territórios africanos e asiáticos, tornando necessário enfatizar-se a missão de levar a “civilização” aos povos "bárbaros” e “selvagens” (SAID, 1990).

Já a situação dos livros didáticos de história do Brasil era mais complexa e polêmica. O Compêndio de história do Brasil, de 1843, elaborado pelo general José Inácio de Abreu e Lima (1796-1869), foi um dos pioneiros.

Esse autor havia participado das guerras da independência na América do Sul com Simon Bolívar e era conhecido por ter pensamentos considerados polêmicos, como o de separar a Igreja do Estado e defender o casamento civil. Apesar disso, e também das suas divergências com o historiador Francisco Adolfo de Varnhagen, o livro didático do general Abreu e Lima foi usado durante anos no Imperial Colégio Pedro II e em diversas instituições do país (MELO, 1997).

Nos anos 1850 a história do Brasil se tornou disciplina independente da história universal, o que exigiu a produção de livros escolares específicos utilizados também pelos professores dos liceus e dos cursos preparatórios para o ensino superior.

Nesta época, quem elaborava os programas e livros didáticos eram os letrados do Instituto Histórico e Geográfico Brasileiro (IHGB), muitos dos quais professores do Colégio Pedro II, cujo sistema de ensino era modelo para todas a escolas secundárias do Império (SCHWARCZ, 1989; CALLARI, 2001).

Um desses professores era o romancista Joaquim Manuel de Macedo, que transformou suas aulas no livro didático “Lições de história do Brasil”. Publicado em 1861, seu livro, seguindo os passos do mestre Varnhagen, contava uma história essencialmente política protagonizada pela elite administrativa e militar e adotava uma abordagem cronológica que incentivava a memorização dos fatos históricos. Além disso, Macedo pregava a necessidade da continuidade e do combate à ruptura entre passado (colônia) e presente (império), principalmente da não-ruptura Portugal e Brasil no momento da independência brasileira e na legitimidade do trono bragantino na direção do novo país. Seu livro didático era um elogio ao projeto colonial português. Destacava, em suas páginas, que havia sido uma obra monumental conduzidas pela Coroa portuguesa. Cada lição terminava com um quadro sinótico e as 
"perguntas" (MATTOS, 2001). O seu livro escolar foi um sucesso, sendo reeditado até 1925 e assim marcando a vida da cultura escolar de muitas gerações (BITTENCOURT, 1990).

Nas primeiras décadas da era republicana a produção historiográfica ainda estava estreitamente vinculada ao IHGB onde, desde a sua fundação, desenvolvia-se o projeto de escrita de uma história nacional. A princípio, os estudos produzidos na esfera do Instituto eram profundamente marcados pela exaltação da monarquia e da colonização portuguesa no Brasil, vista como a responsável pela construção das bases da nação. E a obra de Varnhagen e os livros didáticos de Macedo eram exemplares nesta linha de interpretação histórica e política.

Com o alvorecer da República, as preocupações dirigiram-se para a valorização do novo regime, o prestígio e o elogio da colonização portuguesa sofreram alguns reveses, mas as diretrizes metodológicas básicas do IHGB se preservaram até, pelo menos, o começo dos anos 1930 do século passado. Enfim, continuou-se a confeccionar uma narrativa histórica centrada nos fatos políticos, nos feitos dos grandes homens, nos episódios gigantescos da era dos descobrimentos, da colonização e da ocupação do território brasileiro e, especialmente, na valorização da idéia de unidade nacional (SIMAN; FONSECA, 2001, p. 93).

Nesse momento, a produção dos livros didáticos de História também esteve fortemente atrelada ao IHGB, uma vez que, como já foi observado, muitos historiadores a ele vinculados escreviam os livros mais conhecidos e adotados nos ensino primário e secundário. Estes vínculos garantiram a permanência das formas de interpretação então predominantes da História do Brasil, que passavam do Instituto às salas de aula das escolas por intermédio da mediação dos livros escolares, reforçando-as e difundindo-as.

Professor do Colégio Pedro II e membro do Instituto, autor de trabalhos sobre folclore, história, crítica literária, filologia e gramática da língua portuguesa, João Ribeiro (1860-1934) tornou-se respeitado entre os seus contemporâneos e gerações posteriores como filólogo e historiador. Segundo Patrícia S. Hansen,

Seu livro História do Brasil expressa de maneira bastante eloqüente de que modo algumas das experiências vividas por sua geração implicavam em uma revisão da história do Brasil, fundamentada sobre pressupostos que estavam se tornando hegemônicos na produção historiográfica, para que o ensino da disciplina cumprisse seu papel em um momento considerado decisivo para o destino do país. (HANSEN apud MATTOS, 1998, p. 45).

A sua História do Brasil (Curso Superior), lançada em 1900, inovou na organização dos conteúdos, ao apresentar, além da história nacional, novas unidades temáticas, como as 
que denominou de histórica comum e de história local. Nesse modelo de história, inspirado em von Martius, o autor procurou demonstrar que o Brasil derivou do colono, do jesuíta e do mameluco, da ação dos índios e dos escravos negros, todos personagens principais da sua obra didática. Embora crítico da obra colonial, dedicou grande parte do livro didático para os seus temas: descobrimento, colonização, administração, invasões, ocupação, revoltas entre outros.

Seu livro didático teve várias reedições, chegando a ser adotado ainda em 1964 em escolas públicas de São Paulo e do Rio de Janeiro (MELO, 1997).

Outro autor contemporâneo de João Ribeiro foi o professor e historiador José Francisco da Rocha Pombo (1860-1934). Em sua História do Brasil (Curso superior), na seleção temática, na cronologia e na periodização, tributário também do modelo de von Martius, o autor privilegiou, quanto ao passado colonial, os eventos ligados à conformação territorial e nacional, destacando a organização administrativa, as lutas contra os estrangeiros e os confrontos com a metrópole até a Independência em 1822. Rocha Pombo era um apaixonado pelo tema das bandeiras. Havia uma exaltação aos feitos dos bandeirantes paulistas.

A estrutura do livro de Rocha Pombo não diferiu daquela que se tornou a norma para os livros didáticos brasileiros durante o século XX. De acordo com Thais Nivia Lima e Fonseca

\begin{abstract}
Ele começa situando o mundo o mundo no século XV, a posição dos países ibéricos e especialmente de Portugal no quadro europeu, para enfim chegar à descoberta do Brasil em 1500. Trata das expedições de reconhecimento da terra, fala dos índios, primeiros habitantes, para então adentrar pela política de colonização empreendida por Portugal, com a criação das capitanias hereditárias, seguida da organização do governo geral. Em destaque, aparecem as lutas contra franceses e holandeses, as expedições bandeirantes, as rebeliões do século XVIII nas Minas e o processo de independência, todos eles eventos ligados à formação nacional. (SIMAN; FONSECA, 2001, p. 96).
\end{abstract}

Assim como o livro didático de João Ribeiro, a sua História do Brasil (Curso superior) teve muitas reedições, inclusive uma revista e atualizada pelo historiador Helio Vianna, sendo utilizada nas escolas brasileiras até os anos 1960.

Rocha Pombo faleceu em 1933, sem conseguir tomar posse na Academia Brasileira de Letras. Até essa época da nossa história da educação, o movimento de imposição de um sentido nacionalista à História do Brasil contava com a militância de muitos autores de livros escolares. Além do próprio Rocha Pombo, faziam parte desse grupo Jonathas Serrano, João Ribeiro e Oliveira Lima (BITTENCOURT, 1990). 
Todavia, foi a partir de 1930 que, com a centralização da política educacional, tornaram-se mais explícitas as orientações nacionalistas, tanto para os programas curriculares quanto para os livros didáticos de história do Brasil.

Duas reformas educacionais sucessivas durante a era Vargas - a Francisco Campos, em 1931, e a Gustavo Capanema, em 1942 - prescreveram com maior precisão as diretrizes do ensino de História do Brasil, por meio da implantação dos programas elaborados pelo recémcriado Ministério da Educação. A primeira reforma preocupava-se com a educação política do adolescente e a segunda ampliava essa educação para a formação de uma consciência patriótica (REZNIK, 1992).

Era dentro desta perspectiva nacionalista que os livros didáticos produzidos e utilizados nas escolas brasileiras nos anos 1930 e 1940 montavam sua estrutura e abordagem. Esta linha de pensamento impunha, no discurso didático, uma valorização da atuação dos brasileiros em seu passado histórico, principalmente a partir do momento em que se verificaria o nascimento do sentimento nacional. A colonização portuguesa, por exemplo, sofria críticas, porque era a responsável pelo retardamento do desenvolvimento da nação, graças, sobretudo, aos erros administrativos cometidos pela metrópole. Esta situação teria intensificado o clima de animosidade que, alimentado ao longo de aproximadamente dois séculos, levaria ao rompimento definitivo entre Brasil e Portugal.

Quando havia elogios aos colonizadores, eles eram direcionados aos jesuítas, responsáveis pelo louvável trabalho da catequese. O professor Joaquim Silva, autor de um dos livros didáticos mais adotados desse período, dedicou especial atenção aos missionários religiosos da ordem inaciana.

Para ele, a atuação dos jesuítas ganhou relevância na medida em que teria sido a grande responsável pela consolidação do catolicismo no Brasil, um dos principais elementos conformadores da unidade nacional, pela via religiosa. Para atender a este fim, um bom começo teria sido essencial - o promissor momento da celebração da primeira missa em terras braseiras, em 1500. Ali, a comunhão de portugueses e nativos era o anúncio do futuro da nação ainda não existente, unida pela fé e pela mistura das raças. Impossível aqui não estabelecer uma conexão desta leitura com as alianças políticas varguistas com a Igreja católica. 
Joaquim Silva concentrou especial atenção no período das guerras contra os estrangeiros, sobretudo contra os holandeses, para reforçar seus objetivos de construção de uma consciência patriótica. É neste evento que, fazendo coro com a tradição historiográfica e didática, ele situou o nascimento do sentimento nacional.

Os livros didáticos deste autor ultrapassaram épocas, sendo amplamente utilizados durante o regime militar, instaurado no Brasil pós-1964. Alguns de seus livros chegaram a atingir a marca de 100 edições durante os anos 1960.

A propaganda nacionalista, em especial no período do Estado Novo (1937-1945), espraiou-se por meio de diversos mecanismos, e o ensino de História, mediado pelos livros didáticos, foi um dos mais poderosos. Tanto que deixou raízes profundas no sistema educacional brasileiro, não tendo sido alterado substancialmente até os anos 1980 do século passado (ABUD, 1998).

Desde 1945 até o seu falecimento, o professor Antonio José Borges Hermida (19171995) dedicou a sua vida à produção de livros didáticos de História para o primeiro e segundo graus.

O seu livro didático de História do Brasil seguiu na mesma linha nacionalista de interpretação histórica de Joaquim Silva. Nele, o autor deu especial relevo para os eventos dos descobrimentos portugueses do século XV; a mistura das raças (índios, portugueses e negros); os jesuítas representados como os "amigos dos índios”; a epopéia dos bandeirantes adentrando o interior do país; os ciclos econômicos (pau-brasil, cana-de-açúcar e ouro); as invasões holandesas; a Inconfidência Mineira e a exaltação da figura do mártir Tiradentes.

Para atender ao aumento da demanda de alunos matriculados a partir das reformas educacionais da era Vargas, os livros didáticos passaram a valorizar cada vez mais o uso de ilustrações, mapas e atividades com documentos. Os textos foram elaborados, pouco a pouco, para o aluno e não somente para o professor, cuja formação já vinha sendo realizada na universidade desde os anos 1930. Os livros de Joaquim Silva e Borges Hermida são ilustrativos desta nova mentalidade que tomava conta das páginas dos livros didáticos no país.

As editoras de livros didáticos concentravam-se nesse momento em São Paulo e não mais apenas no Rio de Janeiro. Com o passar dos anos, elas passaram a convidar professores universitários para escrever os novos livros didáticos. Os enfoques variavam entre o político e 
o econômico. Neste último exemplo, a narrativa histórica era dividida em ciclos, que iam do pau-brasil ao ciclo do café e á industrialização (PINSKY, 1994).

Depois da reforma educacional de 1961, os conteúdos tornaram-se menos rígidos. Uma certa influência dos chamados "métodos ativos”, que combatiam o excesso de memorização de nomes e datas, criou algumas inovações, como a coleção organizada pelo historiador paulista Sérgio Buarque de Holanda (1902-1982), abarcando história do Brasil e história geral. Num trabalho com uma equipe de professores universitários, o autor desvinculou-se dos esquemas de memorização, passando a destacar a história da cultura e a documentação iconográfica, principalmente sobre o Brasil. A coleção de Sérgio Buarque inovou ao trazer um conteúdo por série, de acordo com propostas oficiais, além de sugerir o uso didático de documentos de época, como trechos da Carta de Pero Vaz de Caminha. Em termos de conteúdo, o livro didático de Sérgio Buarque continuou a seguir o roteiro trilhado pelos demais autores da tradição didática. O enredo traçado era o mesmo em relação ao Brasil colonial - descobrimento, administração, invasão holandesa, ciclos econômicos, revoltas coloniais e independência.

Durante a ditadura militar (1964-1985), com o crescimento do mercado editorial e a ampliação do número de alunos, sobretudo após a reforma educacional de 1971, ocorreu um aumento significativo da produção didática no Brasil. Novas formas de expressão veiculadas pelos modernos meios de comunicação, em especial a televisão, influenciaram de maneira emblemática na apresentação e linguagens dos livros, colocando em xeque os métodos tradicionais.

Também sofreu mudanças a relação entre o livro didático e o professor. Se antigamente o professor possuía maior autonomia em relação ao uso do livro, pois se pressupunha que a formação docente deveria habilitá-lo integralmente, na nova realidade educacional os professores, principalmente aqueles que tiveram sua formação nos cursos rápidos denominados de Licenciaturas Curtas, passaram a depender com freqüência dos livros para preparar e ministrar suas aulas (RIBEIRO, 2003, p. 17-34).

Numa tentativa de despertar o interesse dos jovens leitores, acostumados com o mundo das imagens e dos sons, os livros didáticos passaram a apresentar ilustrações em grande quantidade, jogos de memorização, além de adotarem cada vez mais os exercícios de múltipla escolha (BITTENCOURT, 2003, p. 52-54). 
No contexto das transformações ocasionadas pela crise do regime militar, o ensino de História encontrou-se diante do dilema de permanecer a difundir a chamada "história oficial" ou de renovar seus objetivos e suas abordagens, seguindo a direção dos ventos que partiam do processo de redemocratização do país entre 1980 e 1989 (NADAI, 1993, p. 143-62).

Diversas foram as propostas de mudanças programáticas e metodológicas, algumas delas ajudando, de maneira efetiva, no abalo das estruturas do tradicionalismo arraigado no ensino da disciplina (FONSECA, 1993).

Na busca de uma atitude mais crítica, muitos autores construíram livros didáticos que não apenas tentavam abandonar a formatação convencional, como também faziam uso de linguagens até então pouco convencionais. Segundo Thais Nivia de Lima e Fonseca,

Textos leves e impregnados do léxico coloquial e o uso de charges como ilustrações foram alguns dos recursos mais utilizados em muitos dos novos livros de História. Cartunistas conhecidos por seu trabalho na imprensa foram, não raro, ilustradores desses livros, dando um viés debochado às abordagens pretendidas. Nesse caso, o risco de banalização da história foi considerável, e alguns livros acabaram por transformar o processo histórico numa revista, às vezes, de gosto duvidoso. (SIMAN; FONSECA, 2001, p. 107).

Devemos ressaltar que diante das chuvas de críticas à produção didática desse período, inclusive do seu comprometimento ideológico, uma nova leva de autores e editores partiram à procura de saídas para manter uma certa qualidade. O aumento dos cursos de pós-graduação, na década de 1970, permitiu uma renovação significativa do conhecimento histórico, trazendo novos problemas, abordagens e objetos (LAPA, 1981).

Os autores profissionalizaram-se cada vez mais, atraídos pelo desafio a frente e, também, pelos rendimentos decorrentes da venda maciça de livros. De acordo com Kazumi Munakata (1997), as lutas pelo retorno da disciplina História e Geografia, e o fim das disciplinas de Estudos Sociais, Educação Moral e Cívica (EMC) e Organização Social e Política do Brasil (OSPB), promoveram mudanças importantes. Como muitos dos autores e alguns editores tiveram formação marxista e haviam participado das lutas pela democratização do país, cresceu a tendência a ensinar história a partir de conceitos como modo de produção e classes sociais. É neste cenário que entraram em cena as coleções História \& Vida, do professor universitário e jornalista Nelson Piletti, em parceria com o seu irmão Claudino Piletti, e Brasil Vivo, do historiador Chico Alencar, em co-autoria com o cientista social Marcus Venicio Ribeiro e o cartunista Claudius Ceccon. 
O livro didático dos irmãos Piletti, para a $5^{\mathrm{a}}$ série do primeiro grau, foi escrito em linguagem simples sem, no entanto, ser banal, bem apropriado para o público ao qual se destinava. Ele é um exemplo do desenvolvimento dos últimos vinte anos da produção didática no Brasil, principalmente pela boa qualidade material, que pode ser visualizada nas ilustrações, resultado de uma criteriosa pesquisa iconográfica e de um cuidadoso tratamento gráfico (SILVA FILHO, 2005). Para Thais Nivia Lima e Fonseca

Além da reprodução de conhecidas obras de arte da pintura brasileira, aparecem muitas gravuras européias, desenhos dos viajantes europeus que estiveram no Brasil desde o século $\mathrm{XV}$, fotografias de situações do presente, desenhos feitos pelos ilustradores da editora, além de uma razoável coleção de mapas históricos. (SIMAN; FONSECA, 2001, p. 111).

O seu livro didático seguiu a cronologia tradicional da História do Brasil, do descobrimento à independência, e procurou criar problematizações como maneira de provocar a reflexão do aluno. Quanto ao tratamento dado à colonização, o autor afirmou que a chegada e a presença dos portugueses no Brasil significou a sua integração ao sistema de comércio internacional do alvorecer dos tempos modernos, visando exclusivamente a aquisição de lucros para a metrópole. E foi com base nesta interpretação econômica que os autores de História \& Vida construíram uma imagem negativa dos portugueses e de sua obra colonizadora, até o acirramento dos conflitos com os brasileiros.

Em diversos momentos, o texto didático tratou do passado à luz do presente dos Piletti. Um exemplo ilustrativo desta atitude foi o fato deles criticarem a destruição das matas do litoral devido à exploração do pau-brasil, explicada pela falta de respeito dos colonizadores em relação às florestas do Brasil, como se fosse possível exigir dos europeus do século XVI uma consciência ecológica nos moldes dos nossos dias (RIBEIRO, 2004).

No caso do processo de formação do sentimento nacional, a guerra contra os holandeses não teve a abordagem amparada no discurso da união das três raças na luta contra o invasor. No seu livro didático, a interpretação concentrou-se nos interesses econômicos em jogo, envolvendo holandeses, comerciantes portugueses e senhores de engenho, estando, dessa forma, mais próximo da historiografia mais recente sobre o assunto.

Os capítulos seguintes do livro foram dedicados ao processo de ocupação e de expansão do território pelos portugueses, esquema que não fugiu ao roteiro já conhecido desde João Capistrano de Abreu e João Ribeiro. 
O professor e historiador carioca Chico Alencar, autor de Brasil Vivo, fazendo uso de títulos de capítulos como "O mundo da terra de todos", "Pai durão, mulher medrosa, filhos assustados!”, “Pau, pano e pão”, “Está nascendo um país” entre outros, procuraram atrair o seu leitor-aluno para uma história tida como mais dinâmica e interessante. Todavia, a proposta inovadora apresentou suas limitações, uma vez que o autor seguiu o enredo cronológico e temático já estabelecidos desde o final do século XIX.

Destinado para os alunos da $5^{\text {a }}$ série do então primeiro grau e publicado no final dos anos 1980, o livro didático de Chico Alencar teve a preocupação de incentivar a reflexão crítica, trabalhando numa perspectiva de desmontagem de "verdades" históricas consolidadas no imaginário nacional. A linguagem, por vezes exacerbada, levou o seu texto didático, em alguns momentos, à beira da banalização, como se ironia e sátira fossem o mesmo que reflexão crítica (SIMAN; FONSECA, 2001). O seu livro didático começou tratando dos primeiros habitantes do Brasil, os índios, apresentados como os verdadeiros heróis de uma saga de violência e destruição, do qual foram as vítimas principais. Mesmo tecendo críticas à narrativa histórica épica e heróica, o autor fez uso destas mesmas noções na construção de uma imagem paradisíaca e romantizada das sociedades indígenas brasileiras (RIBEIRO, 2004).

Em contrapartida, carregaram nas pinceladas ao tratar o colonizador português, ridicularizado por seus costumes, atacados por sua violência e condenados por sua capacidade de destruição. O português era traduzido como uma besta. Neste aspecto, Chico Alencar não fugiu dos textos bem mais antigos, dos republicanos do começo do século XX, conforme observado.

Apesar da proposta inovadora, Brasil Vivo não abriu mão da cronologia tradicional, evidenciando a forte presença da obra da obra de Capistrano de Abreu sobre a historiografia brasileira e sobre a produção didática de História. Descobrimento, ocupação e expansão foram os eixos privilegiados pela nova história do Brasil criada por Chico Alencar.

Em nenhum momento, por exemplo, o autor abordou a questão de um sentimento nacional nascente em meados do século XVII, resultante das invasões holandesa. Por outro lado, a atuação da administração colonial portuguesa foi apontada como responsável maior pelo acirramento dos sentimentos antilusitanos e despertar dos movimentos contra a metrópole, com a mesma ironia e espírito satírico das primeiras páginas do livro didático. 
Os livros didáticos dos irmãos Piletti e de Chico Alencar, editados e amplamente usados nas escolas brasileiras entre 1980 e 2000, foram obras emblemáticas concebidas no bojo das propostas marcadas pela crítica "história oficial” elitizada (CORDEIRO, 1994).

\section{CONSIDERAÇÕES FINAIS}

O objetivo principal deste artigo foi identificar e analisar as permanências e as transformações ocorridas nas práticas discursivas que têm forjado as imagens do Brasil Colonial nos livros didáticos disciplina História, relacionando-as às contribuições dos estudos das Ciências Humanas, desenvolvidos no período, as reformas curriculares e os movimentos sociais. As análises tiveram como ênfase as interpretações elaboradas pelos autores sobre a história do Brasil colonial porque este foi período que a tradição didática e historiográfica tem elegido como a “semente” da nação, que se consolidou em 1822 com a Independência (RIBEIRO, 2004).

Nesta incursão pelo tema, situamos o estudo do tema no âmbito das questões relacionadas à história do livro, explorando as contribuições teóricas e conceituais fornecidas pelos seus historiadores, procurando interligar as questões dos livros didáticos como objeto cultural com as que se referem ao texto escolar e à disciplina História (CHARTIER, 1990; BITTENCOURT, 1993).

O livro didático, na nossa opinião, justificou-se também como objeto rico de pesquisa por se constituir como espaço privilegiado de disputas políticas de constituição de identidades. Nele, há diferentes personagens e modelos de interpretações em jogo. Assim como o currículo para Tomaz Tadeu da Silva (2001), o livro didático é lugar, espaço, território. Objeto de relações de poder por ser trajetória, viagem, expedição, percurso na formação de gerações de leitores-alunos. Ele é autobiografia, nossa vida, nosso curriculum vitae: neste espaço se fabrica nossa identidade. Ele é texto, discurso, documento. É um documento de identidade, uma colônia identitária; objeto de desejo de vários grupos, projetos e políticas. Suas páginas são espaços de políticas ${ }^{4}$. Elas não são a História do Brasil, mas nela são esboçadas as histórias desta “comunidade imaginada”, de múltiplas definições e leituras, batizada de Brasil.

\footnotetext{
${ }^{4}$ Para uma reflexão sobre o conceito de identidade no mundo pós-moderno, cf.: HALL, 2002.
} 


\section{REFERÊNCIAS}

BITTENCOURT, C. M. F. O livro didático não é mais aquele. Nossa História. Rio de Janeiro, ano 1, n. 2, p. 52-54, dez. 2003.

. (Org.). O saber histórico na sala de aula. 2. ed. São Paulo: Contexto, 1998. 175 p.

. Livro didático e conhecimento histórico: uma história do saber escolar. 1993. 269

f. Tese (Doutorado em História Social) - Faculdade de Filosofia, Letras Ciências Humanas, Universidade de São Paulo, São Paulo, 1993.

Pátria, civilização \& trabalho: o ensino de história nas escolas paulistas (19171939). São Paulo: Edições Loyola, 1990. 227 p.

CALLARI, C. R. Os institutos históricos: do patronato de D. Pedro II à construção do Tiradentes. Revista Brasileira de História, São Paulo, v. 21, n. 40, p. 59-82, 2001.

CHARTIER, R. A história cultural: entre práticas e representações. Lisboa: DIFEL, 1990. $239 \mathrm{p}$.

A ordem dos livros: leitores, autores e bibliotecas na Europa entre os séculos XIV e XVIII. 2. ed. Brasília: Editora da UnB, 1999. 111p.

CORDEIRO, J. F. P. A história no centro do debate: da crítica ao ensino ao ensino crítico as propostas de renovação do ensino de história nas décadas de setenta e oitenta. 1994. $239 \mathrm{f}$. Dissertação (Mestrado em Educação) - Faculdade de Educação, Universidade de São Paulo, São Paulo, 1994.

FERRO, M. Falsificações da história. Lisboa: Europa-América, [s.d.]. 280 p.

FONSECA, S. G. Caminhos da história ensinada. Campinas: Papirus, 1993. 169 p.

Didática e prática de ensino de história: experiências, reflexões e aprendizados. Campinas: Papirus, 2003. 255 p.

FONSECA, T. N. L. História \& ensino de história. Belo Horizonte: Autêntica, 2003. 119 p.

FREITAS, M. C. (Org.). Historiografia brasileira em perspectiva. São Paulo: Contexto/EDUSF, 1998. 480 p.

GASPARElLO, A. M. Construtores de identidades: a pedagogia da nação nos livros didáticos da escola secundária brasileira. São Paulo: Iglu Editora, 2004. 240 p.

KARNAL, L. (Org.). História na sala de aula: conceitos, práticas e propostas. São Paulo: Contexto, 2003. 216 p. 
LAPA, J. R. A. História e historiografia: Brasil pós 1964. Rio de Janeiro: Paz e Terra, 1985. $204 \mathrm{p}$.

Historiografia brasileira contemporânea (a história em questão). Petrópolis, RJ: Vozes, 1981. 101 p.

MATTOS, I. R. (Org.). Histórias do ensino da história no Brasil. Rio de Janeiro: Access Editora, 1998. 136p.

MUNAKATA, K. Produzindo livros didáticos e paradidáticos. 1997. 218 f. Tese (Doutorado em Educação) - Pontifícia Universidade Católica de São Paulo, São Paulo, 1997.

MELO, C. F. C. B. Senhores da história: a construção do Brasil em dois manuais de história na segunda metade do século XIX. 1997. 295 f. Tese (Doutorado em Educação) - Faculdade de Educação, Universidade de São Paulo, São Paulo, 1997.

NADAI, E. O ensino de história: trajetória e perspectivas. Revista Brasileira de História. São Paulo, v. 13, n. 25/26, p. 143-62, set./ago. 1993.

PINSKY, J. (Org.). $O$ ensino de história e a criação do fato. 6 ed. São Paulo: Contexto, 1994. 109 p.

RAMINELLI, R. Imagens da colonização. A representação do índio de Caminha a Vieira. Rio de Janeiro: Jorge Zahar Editor, 1996. 186 p.

REIS, J. C. As identidades do Brasil. De Varnhagen a FHC. 2. ed. Rio de Janeiro: Editora FGV, 1999. 278p.

REZNIK, L. Tecendo o amanhã (a história do Brasil no ensino secundário: programas e livros didáticos, 1931 a 1945). 1992. 284 f. Dissertação (Mestrado em Educação) - Instituto de Filosofia e Ciências Sociais, Universidade Federal Fluminense, Niterói, 1992.

RIBEIRO, R. R. Colônia(s) de identidade(s): discursos sobre a raça nos manuais escolares de História do Brasil. 2004. 421 p. Dissertação (Mestrado em História Cultural) - Instituto de Filosofia e Ciências Humanas, Universidade Estadual de Campinas, Campinas, 2004.

- O saber em discurso, projetos e leis: a história ensinada no Brasil entre o II pósguerra e a ditadura militar. ETD - Educação Temática Digital. Campinas, v. 04, n. 02, p. 1734, jun. 2003. Disponível em: http://143.106.58.55/revista/index.php.

SAID, E. Orientalismo: o Oriente como invenção do Ocidente. São Paulo: Companhia das Letras, 1990. 376 p.

SCHWARCZ, L. K. M. O espetáculo das raças: cientistas, instituições e questão racial no Brasil (1870-1930). 3. ed. São Paulo: Companhia das Letras, 1993. 296 p. 
. Guardiões da nossa historia oficial. São Paulo: Idesp, 1989. 78 p.

SCHWARCZ, L. K. M. (Org.). História da vida privada no Brasil 4: contrastes da intimidade contemporânea. São Paulo: Companhia das Letras, 1998. 820 p.

SILVA FILHO, J. B. Os discursos verbais e iconográficos sobre os negros nos livros didáticos de história. 2005. 144 f. Dissertação (Mestrado em Educação) - Faculdade de Educação, Universidade Federal de Minas Gerais, Belo Horizonte, 2005.

SILVA, T. T. A identidade cultural na pós-modernidade. 7. ed. Rio de Janeiro: DP\&A, 2002. $104 \mathrm{p}$.

- Documentos de identidade: uma introdução às teorias do currículo. 2. ed. Belo Horizonte, MG: Autêntica, 2001. 156 p.

- O currículo como fetiche: a poética e a política do texto curricular. Belo Horizonte: Autêntica, 2003. 120 p.

- (Org.). Identidade e diferença: a perspectiva dos Estudos Culturais. 2. ed. Petrópolis: Vozes, 2003. 136p.

SIMAN, L. M. C.; FONSECA, T. N. L. (Org.). Inaugurando a história e construindo a nação: discursos e imagens no ensino de história. Belo Horizonte: Autêntica, 2001. 184 p.

RENILSON ROSA RIBEIRO

Docente do Departamento de História - ICSA/UNEMAT Coordenador de

Estágio Supervisionado em Ensino de História

Doutorando em História Cultural - IFCH/UNICAMP

Mestre em História Cultural - IFCH/UNICAMP

E-mail: rrrenilson@yahoo.com 